\title{
Halkla İlişkiler mi Kurumsal İletişim mi? Akademiden Uygulamaya Kavram Tartışmaları*
}

\author{
Public Relations or Corporate Communication? Concept Discussions of Academics and \\ Professionals
}

\section{Burcu ÖKSÜZ Serra GÖRPE***}

Öz

$\mathrm{Bu}$ çalışmanın amacı, ülkemizde halkla ilişkiler ve kurumsal iletişim arasındaki kavram tartışmalarını akademisyen ve uygulayıcı bakış açısıyla ortaya koyarak, ilgili mevcut literatür ve uygulamaya katkı sağlamaktır. Bu kapsamda İstanbul ve İzmir şehirlerinde çalışan ve çeşitli sektörleri temsil eden halkla ilişkiler-kurumsal iletişim uygulayıcılarıla ve üniversitelerde görev yapan akademisyenlerle yarı yapılandırılmış görüşmeler yapılmıştır. Çalışmada halkla ilişkiler ve kurumsal iletişim kavramlarının nasıl değerlendirildiği, farklılıkların ve benzerliklerin ne olduğu, söz konusu kavramların nasıl tanımlandığı, hangi kavramın tercih edildiği, başarının nasıl tanımlandığı ve başarıyı etkileyen faktörler açısından veriler elde edilmiştir. Araştırmaya katılan uygulayıcıların tamamı kurumsal iletişim kavramını tercih etmektedirler. Bu tercihin nedenleri arasında kurumsal iletişimi daha kapsayıcı olarak görmeleri, işletme işlevine daha yakın olması ve üst yönetimden daha fazla destek görmesi yer almaktadır. Bunların yanı sıra halkla ilişkilerin tarihinden gelen olumsuzluklar da kurumsal iletişimin tercih edilmesine neden olmaktadır. Ancak akademisyenler, kurumsal iletişimi uygulayıcılar kadar tercih etmemektedir. Halkla ilişkiler kavramını tercih eden akademisyenler, bu tercihin nedenlerini halkla ilişkiler kavramının "kamu” yu içermesi ve paydaşlarını ekonomik birim olarak görmemesi olarak açıklamaktadır. Çoğu katılımcı, uygulamalara bakıldığında iki kavram arasında belirgin bir farktan söz edememektedir. Genel olarak kurumsal iletişim ve halkla ilişkilerde başarı benzer şekilde açılanmıştır. Uygulayıcıların benzer niteliklere

* Bu çalışma, Prof. Dr. Alâeddin Asna anısına düzenlenen 'Yeni Zamanlar ve Halkla İlişkiler' adlı konferansta (19-20 Nisan 2018-Ankara) sözlü olarak sunulan bildirinin geliştirilmiş halidir.

** Doç. Dr., İzmir Kâtip Çelebi Üniversitesi, Medya ve İletişim Bölümü, İzmir, Türkiye, burcu.oksuz@ikc.edu.tr. Orcid ID: 0000-0003-4195-9261.

*** Prof. Dr., University of Sharjah, College of Communication, Sharjah, Birleşik Arap Emirlikleri, tgorpe@sharjah.ac.ae. Orcid ID: 0000-0002-9634-2827. 
sahip olması gerektiğinden söz edilmiş ancak bazı katılımcılar, kurumsal iletişim uygulayıcılarının işletme nosyonuna daha fazla hâkim olması gerektiğini vurgulamışlardır. Çalışma halkla ilişkiler eğitimi açısından da değerlendirilmiştir.

Anahtar Sözcükler: Kurumsal İletişim, Halkla İlişkiler, İletişim Uygulamaları, İletişim Eğitimi

\begin{abstract}
The goal of this study is to explore the conceptualization of public relations and corporate communication concepts by academicians and professionals and to contribute to the academic literature and its practice. To investigate perceptions, semi-structured interviews were conducted with practitioners as well as academics in Istanbul and Izmir. Data on how the concepts of public relations and corporate communication are understood and defined, how success is defined, and which factors affect success are gathered. Our findings reveal that all practitioners prefer corporate communication over public relations. They view corporate communication as more comprehensive, closer to the business function, and having more support from top management. The negative past of public relations is stated as another reason. Academics seemed to favor public relation over corporate communication. Academics who preferred the former explained that public relations includes the public, and it does not see its stakeholders as an economic unit only. Most interviewees did not emphasize a prominent difference between corporate communication and public relations. In general, the success factors involved in corporate communication and public relations were reported as being similar. It was mentioned that practitioners have similar qualifications, but some participants stress that corporate communication practitioners need to be knowledgeable about business practices. We also discuss the implications of our findings in terms of public relations education.
\end{abstract}

Keywords: Corporate Communication, Public Relations, Communication Practices, Communication Education

\title{
Giriș
}

Halkla ilişkiler genelde doğru anlaşılmamakta, halkla ilişkiler uygulayıcılarının tam olarak ne yaptığı bilinmemektedir. Bunu sadece toplumdaki bir algı olarak görmenin ötesinde kurum dünyasında halkla ilişkiler uygulayıcılarının sıkça karşılaştığı bir durum olarak da söylemek mümkündür. Halkla ilişkiler diğer oturmuş mesleki alanlarla karşılaştırıldığında değerini topluma, hedef kitlelerine ve müşterilerine ispatlamaya çalışmaktadır. Ayrıca, ülkeden ülkeye gelişme düzeyi farklı olduğu için uygulamasında farklılıklar ve değişik algılanışlar da olmaktadır. Coombs ve Holladay (2007) halkla ilişkilere getirilen eleştirileri altı maddede özetlemektedir. Bu maddeler halkla ilişkilerin gerçeği yansıtmadığı ve tam anlamıyla yalan olmasa bile gerçeği dönüştürdüğü; halkla ilişkilerin köklerinin manipulasyon ve iknaya dayandığı ve özellikle halkla ilişkiler alanındaki ilk çalışmaların etik olmayan ikna ve propaganda eksenli olduğu; halkla ilişkilerin zaten güçlü olan kurumların ve diğer grupların gücüne güç kattığ 1 ; halkla ilişkilerin yalnızca güçlü kurumlara hizmet götürerek onların çıkarlarına hizmet ettiği ve böylelikle demokratik süreci zayıflattığı; toplumun ancak halkla ilişkilerin ne olduğunu tam anlamıyla bilmesiyle kendisini halkla ilişkilerin etkisinden kurtarabileceği ve halkla ilişkilerin yalnızca duyurum ve medyada görünürlük çalışmalarıyla sınırlı olduğudur (s. 14-16). 
Kurumsal iletişim her geçen gün daha da yaygınlaşarak kullanılmakta ve halkla ilişkiler diye adlandırılan bir yönetim işlevini içermektedir. Steyn ve Puth (2010) kurumsal iletişim kavramının günümüz çağdaş örgütlerinin gereksinimi olan daha "doğru (sahi) ve geçerli" bir tanımlamayı içerdiğini ve kurumsal iletişim kavramı kullanımının 1992 gibi eski tarihlerden beri halkla ilişkiler yerine tercih edildiğini belirtmektedirler (s. 2-3). Halkla ilişkiler isminin boşaltılmasını gerekçe göstererek halkla ilişkileri yalnızca kurumsal iletişimle özdeşleştirmek doğru olmayacaktır. Günümüzde Türkiye’de ve dünyada halkla ilişkiler adıyla lisans ve lisansüstü bölümler bulunmakta, akademik araştırmalar yapılmakta, hakemli bilimsel dergiler ve kitaplar yayınlanmaktadır. Diğer bir deyişle halkla ilişkiler akademik literatürde yerleşmiş durumdadır (Tuncel, 2009, s. 121-122).

Halkla ilişkiler medya tarafından yanlış kullanılmakta ve dolayısıyla toplum tarafından da doğru algılanmamaktadır. Manipülasyon, propaganda, kurumların çıkarlarına hizmet etmek için yalan söylemek ve imaj oluşturmak halkla ilişkiler ile özdeşleştirilen sıfatlar ve tanımlamalardır. Halkla ilişkilerin medyada görünürlüğüyle ilgili çeşitli ülkelerde yapılan çalışmalar bu algılanışı da sergilemektedir (Woo, Gorpe ve Kalupa, 2013). Kısaca günlük dilde halkla ilişkiler, halkla ilişkilerin doğasını ve uygulamasını doğru bir şekilde aktaramamaktadır. Oysa halkla ilişkilerin akademik kavramsallaştırılması demokratik unsurları içerir, diyalogdan bahseder, örgütler ve paydaşların ilişkilerinde karşsılıklılık ve bağımlılığı vurgular (Coombs ve Holladay, 2007, s. 12).

Kurumsal iletişim alanına yönetim ve örgütsel teori, halkla ilişkiler ve kitle iletişim disiplinleri tarafından düzenli ve artan bir ilgi bulunmaktadır. Bunun bir sonucu olarak, kurumsal iletişimle ilgili gerek kuramsal gerekse ampirik bir çok çalışma ortaya konulmuştur. Bunlar arasında kurumun paydaşlarına kendisini sunma süreçleri ve biçimleri, kurumsal sosyal sorumluluk, sürdürebilirlilik, kurumsal vatandaşlı gibi kavramların paydaşlarla iletişimde etkisi ve stratejik olarak kurumsal iletişimcilerin varlığı ile oluşturdukları süreçler ve sistemler yer almaktadır (Christensen ve Cornelissen, 2011 s. 384). "Kurumsal iletişimciler, bir iletişim disiplini ve yönetim işlevi olan halkla ilişkileri kurumsal yapılarda kullanan profesyoneller olarak kabul edilebilir. Halkla ilişkiler sadece kurumsal iletişimde değil, ürünlerin pazarlanmasında yani pazarlama iletişiminde, ayrıca siyasette, diplomaside, devlet yönetiminde de kullanılmaktadır” (Tuncel, 2009, s. 122). Halkla ilişkiler departmanlarının Amerika’da kurum dünyasındaki gelişimine baktığımızda, başlangıçta ilk işlevinin tanıtım ve duyurum amaçlı olduğu belirtilmektedir (Wilcox ve Cameron, 2012). Daha sonra bu işlevler evrilmiş; bütünleşik pazarlama iletişimi, bütünleşik iletişim ya da bütünsel iletişim gibi adlarla ifade edilen bütünsel bakış içinde halkla ilişkilerin iş hedeflerinin önemli bir parçası olduğu vurgulanmıştır.

Tosun (2003), kurumsal iletişimin halkla ilişkiler ile eşanlamlı olarak değerlendirilmesinin doğru olmadığını, kurumsal iletişimin bileşenleri arasında gösterilen 'yönetim iletişimi', 'organizasyonel iletişim' ve 'bütünleşik pazarlama iletişimi' çalışmalarından yönetim iletişimi ve bütünleşik pazarlama iletişiminin her zaman halkla ilişkiler ağırlıklı çalışmayabileceğini vurgulamaktadır (s. 176). Halkla ilişkilerin pazarlama iletişimine katkı sağlayan yönü olan pazarlama yönelimli halkla ilişkilerin halkla ilişkilerin tarihinden geldiği vurgulanmaktadır. Pazarlama yönelimli halkla ilişkilere verilebilecek örneklerden biri, Edward Bernays’in kadınları sigara içmeye özendiren 1929 tarihli sigara kampanyasıdır. Pazarlama yönelimli halkla ilişkilerin savuncularından olan Thomas Harris 
ise halkla ilişkilerin tüketici hedef kitleyi çok iyi anladığını ve günümüzdeki başarılı uygulamalara bakarak, halkla ilişkilerin itibara yönelik katkılarının pazarlama üzerinde de görüldüğünü söylemektedir (Akt. Smith, 2009, s. 5-8).

$\mathrm{Bu}$ çalışma, halkla ilişkiler ve kurumsal iletişimin gelişim ve kavramlarına yönelik bir değerlendirme sonrası Türk halkla ilişkiler akademisyenleri ile halkla ilişkiler kurumsal iletişim yöneticilerinin bu iki kavramı algılayışına yönelik bir araştırmayı içermektedir. Araştırma, kavram olarak değerlendirme ve tanımlanmanın yanı sıra iki kavram arasında benzerlikler ve farklılıklar bağlamında bir analizi de içermektedir. Ayrıca kurumsal iletişimde başarıyı etkileyen etmenler ve başarılı bir halkla ilişkiler ve kurumsal iletişimcinin nitelikleri de çalışmanın içinde yer almaktadır.

\section{Halkla İlişkiler}

Çağdaş anlamıyla halkla ilişkiler uygulamaları, Türkiye'de ilk kez 1960'l yıllarda devlet sektöründe başlamış, muhtemelen devletin vatandaşlarıyla kurduğu ilişkiyi anlatması için İngilizcedeki public relations terimi Türkçeye önce amme münasebetleri, sonra halkla münasebetler ardından ise halkla ilişkiler olarak çevrilmiştir (Tuncel, 2009, s. 110). Public relations kavramının Türkçe’ye halkla ilişkiler olarak çevrilmesi ile halkla ilişkilerin anlamlandırma sorunu başlamıştır. Halk sözcüğünün genelllikle kamu/toplum olarak algılanmasından dolayı halkla ilişkiler kavramı uzun zaman toplumla/kamuyla ilişkiler olarak açıklanmıştır. İlişsi sözcüğünün de halkla ilişkiler mesleğinin diğer kişilerle ilişki kurması şeklinde algılanmasına yol açmasından ötürü, kavrama büyük bir sınırlama gelmiş ve bu durum halkla ilişkilerin dar kapsamlı görülmesine neden olmuştur (Temel Eğinli, 2014, s. 67). Halkla ilişkilerin kavramsal olarak public relations teriminin anlamını tam karşılamadığına, çevirinin zorlama olduğuna ilişkin eleştiriler, uygulamada ve akademik literatürde yıllarca devam etmiştir. İngilizcedeki public, yalnızca vatandaşlar anlamındaki halkı değil "bir kurumun, grubun veya kişinin bilerek veya bilmeyerek etkileşimde bulunduğu bütün hedef kitlelerini” anlatmaktadır (Tuncel, 2009, s. 110).

Hutton (1999) halkla ilişkilerin genellikle kendisi tarafından yaratılan bir kimlik krizinden mustarip olduğunu ileri sürer. Halkla ilişkiler, hem teoride hem de uygulamada temel amacı, egemen metaforu, faaliyet alanı ve temelleri açısından genel kabul görmüş bir tanıma ulaşmakta başarısız olmuştur (s. 199). ABD'de public relations kavramına ilişkin sorunun temeline ilişkin literatürde ve uygulamacılar tarafından yapılan tartışmalarda, kavramın alanın yeni içeriğini ve sınırlarını karşılamıyor olduğu konuşulmaktadır. Halkla ilişkiler artık kurumdan daha çok ilgili kamular ve müşteri odaklıdır (Yıldız, 2010, s. 25). Tuncel (2009) ABD'de ve İngiltere'de public relations kavramının özellikle uygulamada kullanılmasından duyulan çekinceler nedeniyle halkla ilişkiler yerine alternatif açılımlar önerildiğini, bu durumun 1990'lı yılların ortalarında Türkiye’ye de yansıdığını ve geleneksel halkla ilişkiler yaklaşımının birçok idealist meslek mensubunu, gazetecileri ve büyük kurumları rahatsız ettiğini vurgular (s. 119).

Halkla ilişkiler ne olduğuyla değil, ne yaptığıyla karakterize edilen bir alan olmuştur. Bir uygulayıcıdan halkla ilişkileri tanımlaması istendiğinde, duyurum elde etmek, basın ajanslığı, (kurumsal) reklamclık, olay yönetimi ve medya ilişkileri gibi yaptığı işlerin bir listesini sıralaması 
olasıdır (Köseoğlu, 2014, s. 11). Halkla ilişkiler tanımlarına yönelik temel bir eleştiri, temel amacından ziyade halkla ilişkilerin etkilerine ve/veya uygulayıcıların belirli görevlerine odaklanmasıdır. Diğer yaygın bir eleştiri, akademik tanımların ticaret ve politikada halkla ilişkilerin gerçek fonksiyonuna ilişkin tanımlamadan ziyade normatif veya buyurucudur (Hutton, 1999, s. 201). Tekvar (2017) ise yakın zamana kadar halkla ilişkilerin, "iletişim çalışmalarına bağlı olarak örgütün amaçlarına ulaşmasında kullanılan planlı iletişim çalışmaları" olarak anlamlandırıldığını, gerek halkla ilişkilerin gerekse iletişim çalışmalarının uzun süre tek yönlü ve tek yanlı, pozitivist, mekaniksel, monoloğa dayalı yorumlandığının altını çizmektedir (s. 83).

Kalender (2013) halkla ilişkilerin yönetim fonksiyonu ya da iletişim yönetimi olarak tanımlandığını ancak son zamanlarda halkla ilişkileri ilişki yönetimi olarak gören tanımların da olduğunu vurgulamaktadır (s. 4). Benzer şekilde Yıldız (2010), "halkla ilişkiler alanına örgüt ve ilgili kamuları arasında anlayış geliştirme’ gibi çok klasik, çok genellemeci bir tanımla bakmak yerine, ilgili kamuları değiştirerek toplumu ve dünyayı değiştiren ya da bu ayrıcalığı elinde tutan bir alan olarak bakmak göz ardı edilemez bir durum" olduğunu belirtmektedir (s. 25). Halkla ilişkilerin temel ilkesi, halka-kamuoyuna doğru bilgiler sunmak, meşruluktan ayrılmadan kurum ya da kişi hakkında olumlu imaj oluşturmaya çalışmak ve karşılıklı anlayış sağlamaktır (Canöz, 2008, s. 141). Halkla ilişkilerin amac1, kurumun hedef gruplara faaliyetlerinin benimsetilmesi yerine onay ve kabülün karşılıklı anlayış, iyi niyet ve hoşgörüyle oluşmasıdır. Bu amacın gerçekleştirilmesi, kamularının istek, beklenti ve ihtiyaçlarından haberdar olunması, kurumun beklenti, amaç ve isteklerinden de hedef kitlelerin haberdar edilmesine bağlidır (Ertürk, 2016, s. 211). Karşılıklı anlayış ve iyi niyetin geliştirilmesi temeline dayalı olan halkla ilişkilerin tanımlarındaki ortak vurgu, "kurumlar ve ilgili çevreleri arasında karşlıklı anlayış ve iyi niyeti oluşturmak ve sürdürmektir” (Kalender, 2013, s. 6).

Halkla ilişkiler üç farklı anlamda değerlendirilmektedir. Birincisi iknaya yönelik olup örgütün hedef kitleleriyle ikna amaçlı iletişimini içerir. Bu anlamın içinde halkla ilişkiler modellerinde yer alan basın ajansı-duyurum, kamouyunu bilgilendirme ve iki yönlü asimetrik halkla ilişkiler modelleri yer alır. Halkla ilişkilerin ikinci anlamı, ilişki yönetimiyle ilgilidir. Bu durum sistem teorisi ile ilişkili olup, halkla ilişkileri örgütü çevre sistemine bağlayan bir alt sistem olarak tanımlar. Üçüncü anlam, halkla ilişkileri işlevsel perspektiften kaydırarak, birlikte anlam oluşturmaya yönelik bir perspektife dayandırır. Bu durumda halkla ilişkiler örgütün konumlandırılmasında ve itibarında bir araçtır. Bunu başarabilmekteki kilit nokta ise halkla ilişkilerin teknisyen rolünden çıkıp, yönetsel rolü üstlenebilmesidir (Mazzei, 2014, s. 221). van Ruler ve Vercic (2002) Avrupa'da halkla ilişkilerin dört karakteristiğini şöyle açıklamaktadır:

Yansıtıcı: Toplumdaki değişen standartları, değerleri ve görüşleri analiz etmek, bunları örgüt üyeleriyle tartışmak, örgütün standartlara, değerlere ve görüşlere uyumunu sağlamak. Bu rol örgütsel standartlar, değerler ve görüşlerle ilgilidir ve örgütsel misyonun ve stratejilerin geliştirilmesini amaçlamaktadır.

Yönetsel: Güven ve/veya anlayış kazanmak amacıyla paydaş gruplarla iletişim kurma ve ilişkileri sürdürme planlarının geliştirilmesi. Bu rol ticari ve diğer (içsel ve dişsal) paydaş grupları ve kamuoyuyla ilgilidir ve örgütsel misyon ve stratejilerin uygulanmasını amaçlamaktadır. 
Operasyonel: $\mathrm{Bu}$ rol iletişim planlarının uygulanmasıyla ilgilidir.

Eğitimsel: Sosyal taleplere cevap verilebilmesi amacıyla örgütün tüm üyelerinin yetkin şekilde iletişim kurmasına destek olunması. Bu rol örgüt üyelerinin zihinleri ve davranışlarıyla ilgilidir ve içsel paydaş gruplarını amaçlar. (s. 14)

Grunig (2009) ise halkla ilişkilerin temel ilkelerini şöyle özetlemektedir:

Halkla ilişkilerin güçlendirilmesi: İletişim yöneticinin örgütle ilgili kararların alındığı üst yönetimin parçası olması veya üst yönetime ulaşabilmesi.

Entegre iletişim fonksiyonu: Tüm halkla ilişkiler fonksiyonlarının entegre edilmesi veya farklı iletişim faaliyetlerinden sorumlu bölümleri koordine eden bir mekanizmanın varlığı.

Ayrı yönetim fonksiyonu: Bazı örgütler halkla ilişkiler fonksiyonunu pazarlama, insan kaynakları, hukuk, finans gibi diğer departmanları destekleyen bir araç gibi bölmektedir.

İletişim teknisyeni veya idari yöneticiden çok stratejik yöneticiler tarafından yönetilmelidir: İletişim teknisyenleri günlük iletişim faaliyetlerinin yerine getirilmesinde temeldir. Ancak muhteșem halkla ilişkiler birimleri halkla ilişkiler programlarını yöneten en az bir üst yöneticiye sahip olmalıdır.

Stratejik yönetimde yer almalıdır: Halkla ilişkiler örgütsel kararların ve davranışların sonuçlarını etkileyen hem iç hem de dış stratejik paydaşlarla iletişim kurmaya yönelik programlar geliştirmektedir.

İki yönlü ve simetrik iletişim: Hem iç hem de stratejik paydaşlarla çatışmaların yönetilmesi ve ilişkilerin geliştirilmesinde araştırmada, dinlemede ve diyalogda iki yönlü simetrik halkla ilişkilerin kullanılması.

Farklılık: Etkili örgütler çevrelerinde farklılık arttı̆̆ı zaman halkla ilişkiler fonksiyonlarında farklılığ ${ }_{1}$ arttırma girişiminde bulunurlar.

Etik: Halkla ilişkiler departmanları uygulamalarını etik şekilde yürütmeli ve etik ve sosyal açıdan sorumlu örgütsel kararları ve davranışları desteklemelidir. (s. 2)

\section{Kurumsal İletişim}

Kurumsal iletişim literatürü 1970'li yıllara kadar gitse de, bu dönemde kurumsal iletişim, kurumsal halkla ilişkiler olarak biliniyordu ve kurumlardaki halkla ilişkiler departmanlarının sorumluluğundaydı (Mohamad ve Bakar, 2018, s. 240). Podnar (2015) kurumsal iletişimi bir kurumun iletişiminin farklı yönlerinin senkronizasyonu ve bu kurum tarafından gönderilen mesajların entegrasyonu olarak tanımlamaktadır (s. 4-5). van Riel (1995) ise kurumsal iletişimi paydaşlara yönelik iç ve dış tüm iletişim şekillerinin harmonize edildiği yönetsel bir enstrüman olarak açıklamaktadır (s. 1). Diğer bir tanımda kurumsal iletişim, "[g]enel olarak işletmelerin amaçlarına ulaşmak ve amaçlarını gerçekleştirmeye yönelik stratejilerini uygulamak için planladıkları tüm iletişim çalışmalarının bir entegrasyonudur." (Tosun, 2003, s. 175). Podnar (2015) kurumsal iletişimin kurumların iletişiminde disiplinlerarası bir bakışa odaklandığını ve iletişimi kurumun 
mevcudiyetini, motivasyonunu ve gelişimini sağlayan bir kaynak olarak gördüğünü belirtmektir. Mihai (2017) ise kurumsal iletişim yönetiminin halkla ilişkiler, içsel iletişim, yatırımcı etkileşimi ve kurumsal reklamcıllğın yönetimini içerdiğini vurgulamaktadır (s. 104).

Kurumsal iletişime yönelik tanımlar birçok ders kitabında kriz iletişimi, medya ilişkileri, yatırımcılarla ilişkiler, çalışanlarla ilişkiler ya da yakın çevre ilişkileri gibi farklı aktiviteleri sıralandırarak geleneksel olarak halkla ilişkilerin geniş alanı içinde bulunan alanları sıralar. Bunlar arasındaki farkın ne olduğundan bahsedilmez ve kurumsal iletişim halkla ilişkilerin daha sofistike ve çağdaş hali olarak sunulur. Kurumsal temele daha fazla dayanan çalışmalarda ise kurumsal iletişim, diğer iletişim çalışmaları olarak sınıflandırılır. (Christensen ve Cornelissen, 2011, s. 384). Örneğin, van Riel ve Fombrun (2007) kurumsal iletişimi yönetim iletişimi, örgütsel iletişim ve pazarlama iletişimi olmak üzere üç boyuta ayırmaktadır:

Yönetim iletişimi: Örgütün yönetimi ile iç ve dış kitleler arasındaki iletişimi ifade eder.

Pazarlama iletişimi: Temel olarak markayı, ürün ve hizmet satışlarını desteleyen iletişimden oluşmaktadır.

Örgütsel iletişim: Halkla ilişkiler, kamu ilişkileri, yatırımcı ilişkileri, kurumsal reklamclık, çevresel iletişim ve içsel iletişimden oluşmaktadır. (s. 15-16)

van Riel'in (1995) kurumsal iletişimle ilgili eski tanımlarından biri, kurumsal iletişimi "bütünsel iş mesajını" vermek için tasarlanan ve her şeyi kapsayan bir çerçeveye sokar. Bu anlayışta mesajların orkestrasyonu, yani uyumlu bir biçimde düzenlenmesi önem taşır. van Riel ve Fombrun'un (2007) daha güncel tanımları ise kurumsal iletişim "firmanın dayandığı paydaşlar nezdinde olumlu başlangıç noktaları oluşturmak adına bir dizi aktiviterle hem iç hem de dış iletişimin yönetilmesi ve orkestrasyonu" olarak ifade edilir (s. 25). Çağdaş kurumsal iletişimin anlamı farklı departmanların farklı kimlikler içinde iş yürütmesi değil, tek bir başlık altında tüm iletişimi yönetmektir. Bir başka deyişle kurumsal iletişimin farklı iletişim disiplinlerini içeriyor olmasından daha önemli olan, onun çağdaş yönetim anlayışına bir vizyon sağlıyor olmasıdır (Illia ve Balmer, 2012, s. 417).

Kurumsal iletişimle ilgili tanımlar, Amerika'da stratejik yönetimle ilgili olup Avrupa'da ise daha çok kuram temellidir. Yapılan tanımlardaki ortak noktalar üç noktada özetlenebilir. Birincisi, kurumsal iletişimin stratejik bir yönetim işlevi olarak iletişim aktivitelerine stratejik olarak yaklaşması ve kurumun genel stratejisine bağlı olma durumudur. İkinci nokta, iç ve dış iletişim etkinliklerini birleştirerek olumlu imaj ve itibar oluşturma, koruma veya değiştirmeye çalışılmasıdır. Son olarak, tüm söz konusu aktivitelerde kurumun iç ve dış paydaşlarının dikkate alınarak planlanması yer alır (Mazzei, 2014, s. 222-223).

Kurumsal iletişimcinin rolü kurumların günlük faaliyetlerinde ve değer yaratılmasında giderek daha hayati olmaktadır (Jain ve Bain, 2017, s. 4). Zerfass’a (2008) göre kurumsal iletişim, ilk aşamada bilgilendirmeyi ve anlam yaratmayı amaçlamaktadır. Buna dayanarak paydaşları etkilemeyi hedeflemektedir. Kurumsal iletişim bundan dolayı hem ürün ve hizmetlerin sağlanmasına (başarı) hem de kurumlarda soyut değerlerin yaratılmasına (gelecekteki potansiyel başarı) hizmet etmektedir (s. 60). Kurumsal iletişim çevrenin dinlenmesi ve çevreden öğrenilmesi için değerli bir kaynaktır. 
Aynı zamanda kurumun yeniden konumlandırılması ve uyum stratejilerine destek olmaktadır ve kurumsal faaliyetleri destekleyen geniş kapsamlı bir çerçeve yaratılmasının kilit bir faktörüdür (Zerfass ve Viertmann, 2017, s. 72).

Kurumsal iletişim; halkla ilişkiler, bütünleşik pazarlama iletişimi, bütünsel kurumsal iletişim ve kurumsal iletişim boşlukları olmak üzere farklı yaklaşımlarla açıklanabilir. Birinci grup kilit paydaş gruplarının beklentilerindeki boşlukları anlamaya çalışır ve önemli grupları analiz ederek iletişim davranışlarını ve boşlukları anlamaya çalışır. Bütünleşik pazarlama iletişiminin de nihai amacı, kurumsal stratejiye destek sağlamaktır ve dolayısıyla kendisi için kilit hedef kitle olan tüketici ve tedarikçilerin algılarını ve inaçlarını analiz eder. Bütünsel kurumsal iletişim ise üç boyuttan oluşur. Birincil iletişim; ürünün, hizmetin, yönetimin, çalışanların ve kurumsal davranışın iletişime etkileridir. İkincil iletişim, kontrol edilmiş iletişimin etkilerini kapsar. Üçüncül iletişim ise rakipler, medya, çıkar grupları gibi üçüncü partilerin yarattığı iletişim etkilerini içerir. Son olarak kurumsal iletişim boşlukları, paydaşların beklentilerini anlama ve paydaşlarla kurumların ilişkilerini sağlıklı yürütmeyi kapsar, ancak bu durumda analiz örgütün içine, örgütün sistemine, işleyişine bakılarak yapılır ve kötü yönetim nedeniyle olan boşluklara odaklanır (Illia ve Balmer, 2012, s. 422).

Cornelissen (2008) kurumsal iletişimin çok genel anlamda kurumlardan, özellikle büyük kurumlardan mesaj akışı olarak anlaşıldığını belirtse de, günümüzde bu anlayışın birçok farklı örgüte uygulanabileceğinin altını çizmektedir. Kurumsal iletişim ile diğer iletişim türleri arasında fark vardır. Örneğin, reklam ve çalışanlarla ilişkiler gibi diğer iletişim türlerinin çok belirgin hedef kitleleri bulunmaktadır, ancak kurumsal iletişim için bu söz konusu değildir. Kurumsal iletişim, farklı paydaşlarda olumlu ve birbirleriyle uyumlu kurumsal itibar oluşturmak ve korumak için vardır (s. 23). Kurumsal iletişimin geniş alanı içinde tek ya da ortak bir zihniyet bulunmaktadır: 'örgütün iletişimine tamlık ve bütünlükle yaklaşmak'. Köklerine baktığımızda Latince'den gelen "corpus" (corporate) kolektif (toplu) bir varlığın bir vücutta birleşmesi anlamına gelmektedir ki, bu da mecazi olarak birlik ve bütünlüğü çağrıştırmaktadır (Christensen ve Cornelissen, 2011, s. 387).

Kurumsal iletişim, çeşitli araştırmacılar ve akademisyenler tarafından ön plana çıkartılan üç temel hedefi olan bir yönetim işlevidir. Hedeflerden biri, kurumun bağlı olduğu gruplar ile iyi ilişkiler kurmaktır. Bir diğeri, sosyal eğilimleri değerlendirerek ve kurumsal politikalar sunarak kurumun kendisini yenilemesine ve proaktif bir şekilde toplumdaki değişikliklere ayak uydurmasına yardımcı olmaktır. Kurumsal iletişimin diğer bir işlevi, tüm iletişimi tek bir strateji altına yerleştirerek, pazarlama etkinliklerini desteklemektir (Illia ve Balmer, 2012, s. 418).

\section{Amaç ve Yöntem}

Halkla ilişkiler ve kurumsal iletişimin kapsamı ve uygulamaları açısından gerek akademide gerekse uygulamada görüş farklılıkları bulunmaktadır. Bu kapsamda çalışmanın amacı, halkla ilişkiler ve kurumsal iletişim arasındaki kavram tartışmalarını akademisyen ve uygulayıcı bakış açısıyla ortaya koymak ve bu konuyla ilgili literatür ve uygulamaya katkı sağlamaktır. Çalışma kapsamında İstanbul ve İzmir şehirlerinde çalışan halkla ilişkiler/kurumsal iletişim uygulayıcılarıyla ve üniversitelerde görev yapan akademisyenlerle yarı-yapılandırılmış derinlemesine görüşmeler 
yapılmıştır. 28 Mart-14 Nisan 2018 tarihleri arasında yüz yüze yapılan görüşmeler, 30-90 dakika arası sürmüştür.

Katılımcılarla ilgili bilgiler şöyledir:

- 8 Uygulayıcı (Sektörler: sağlık, enerji, otomotiv, gıda, eğitim, kamu, beyaz eşya)

- 6 Akademisyen (4 Profesör-2 Doçent)

\section{Bulgular}

Çalışma kapsamında halkla ilişkiler ve kurumsal iletişim kavramlarının nasıl değerlendirildiği, farklılıkların ve benzerliklerin ne olduğu, kavramların nasıl tanımlandıkları, hangi kavramın daha çok tercih edildiği, başarının nasıl görüldüğü açısından detaylı veriler elde edilmiştir.

\section{Halkla İlişkiler ve Kurumsal İletişim Aynı Mı?}

Katılımcıların halkla ilişkilerle kurumsal iletişsimin aynı olup olmadığına dair farklı görüşleri bulunmaktadır. Bazı katılımcılar, kurumsal iletişimi bazıları ise halkla ilişkileri daha kapsamlı görmektedir. Bunun yanında uygulama açısından farklılıklar olmasa da isim değişikliği yapıldığını, kurumsal iletişimin son zamanda daha popüler olduğunu ve farklı kavramlar tercih edilmesinin yalnızca halkla ilişkiler kavramının eskimesinden/olumsuz imajından kaynaklandığını vurgulayanlar olmuştur. Bu görüşlerden bazıları şöyledir:

...Halkla ilişkiler ve kurumsal iletişim birbirinden ayrı. Ama piyasaya girdiğinizde böyle bir ayrım yok. Sektörde kullanılan anlamıyla fark yok. Orada halkla ilişkiler pazarlama iletişimi de yapıyor marka yönetimi de. Teorik olarak iki kavram farklı. Uygulamada aynı. Kurumsal iletişim deyince halkla ilişkilerin üzerindeki olumsuzluklardan kurtuluyorsun. Ama uygulamaya baktığında aynı şeyleri yapıyorsun. (Akademisyen 3)

...Yaptığımız iş aynı. Sadece sektörde isim değişikliği yönelimi olduğu için şirketler departman isimlerini değiştiriyor. Hem kurumsal iletişim, hem de halkla ilişkiler için aynı uygulamaları sayarım. Medya ilişkileri, sosyal medya, paydaş ilişkileri, organizasyon, kriz iletişimi vs. (Uygulayıcı 4)

Halkla ilişkiler oturmamışken kurumsal iletişim geldi. Eski çalıştığım holding halkla ilişkiler müdürlüğü bölümünün adını kurumsal iletişim olarak değiştirdi. Aynı uygulamalar. Sadece adı değişti. İşleyiş değişmedi. Her yerde de böyle. (Uygulayıcı 1)

Mesleğin en önemli problemi ismi. Kurumsal iletişim ise eksik bırakıyor. Kurumsal iletişim çok pazarlama, çok reklam. (Akademisyen 4)

...Kurumsal iletişimin pratikte halkla ilişkiler uygulamalarından çok fazla ayrıştığını düşünmüyorum. (Akademisyen 6)

...Moda oldu. Herkes departman adını kurumsal iletişim olarak değiştiriyor. Departmanda hiç birşey değişmiyor (Akademisyen 3) 


\section{Hangi Kavram Tercih Ediliyor?}

Uygulayıcılardan yedi tanesi kurumsal iletişim, bir tanesi ise kurumsal iletişim veya iletişim kavramını tercih etmektedir. Akademisyenlerden üçü halkla ilişkiler, biri kurumsal iletişim veya halkla ilişkiler, ikisi ise kurumsal iletişim kavramını kullanmayı tercih etmektedir. Dolayısıyla sektörde daha çok kurumsal iletişim kavramının tercih edildiğini söylemek yanlış olmayacaktır.

\section{Neden Halkla İlişkiler Kavramı Tercih Ediliyor?}

Halkla ilişkiler kavramını kullanmayı tercih eden akademisyenler, tercihlerinin nedenlerini aşağıdaki şekilde açıklamaktadır:

...İdeal anlamda halkla ilişkiler itibar kazandırır. Kurumsal iletişim başlığı, kişi düzeyindeki iletişimi dışarıda bırakıyor. Halkla ilişkileri, ben pazarlama ve pazarlama iletişiminden ayırıyorum. Halkla ilişkiler paydaşlar/kamularla iletişim kurar. Paydaşlarını ekonomik birim olarak göremez. Ekonomik birim olarak görürseniz, çift yönlü ilişkiler kuramazsınız. Halkla ilişkiler yansıtıcı paradigmaya yaklaşmalı. Halkla ilişkilerin bagajı, geçmişinden gelen sorunlar, geçmişinden getirdikleri nedeniyle çok da iyi algılanmayan imajı - itibarı. Bernays, propaganda çok savaşla ilişkiliydi, bundan dolayı halkla ilişkiler dedim diyor. Kurumsal iletişim kavramının kullanılması, geçmişteki bağı koparmak için. (Akademisyen 3)

...Halkla ilişkilerci, kamuların kurumdaki temsilcisi. Kamuların kurumu daha iyi anlamasını, daha iyi bilgi edinmesini sağllyor (Akademisyen 4)

...Temel olduğu için halkla ilişkileri tercih ediyorum. Halkla ilişkilerin tarihsel evriminde reklam ve pazarlama bakış açısı var. Halkla ilişkiler kamu beklentilerinden ziyade kurum beklentileri. (Akademisyen 5)

\section{Neden Kurumsal İletişim Kavramı Tercih Ediliyor?}

Kurumsal iletişim kavramını tercih eden katılımcılar, tercihlerinin nedenlerini ve neden bu kavramın halkla ilişkilerin yerine kullanıldı̆̆ını farklı şekillerde açıklamaktadır. Görüşlerden bazıları şöyledir:

...Beni başından beri rahatsız eden nokta, halkla ilişkilerin kurum üzerinden yapılan iletişim olması. Kurumsal iletişimin temel dayanakları var, paydaş teorisi ve kültür ve kimlik. (Akademisyen 5)

...Kurumsal iletişimi tercih ediyorum. İngilizce anlamına baktığında halkla ilişkiler çok durumu kapsayıcı. İş dünyasında yanlış anlaşılmamak için, halkla ilişkilerin yanlı anlamından dolayı kurumsal iletişim diyoruz. Altı kurumda çalıştım. Altısında da kurumsal iletişim adı altında. (Uygulayıcı 2)

...Kurumsal iletişim olunca çok havalı geliyor insanlara. Ama isim halkla ilişkiler olunca ne yapıyorsunuz ki iki tane organizasyon yapıyorsunuz, fotoğraf çekiyorsunuz deniliyor. (Uygulayıc1 3) 
...Halkla ilişkiler bugünün iş hayatını karşılamıyor. İyi bir şeymiş. Kurumsal iletişim 101 gibi görüyorsunuz. (Uygulayıc1 6)

...Halkla ilişkiler kurumsal iletişime hizmet eden destek birimi. Asıl çatının iletişim departmanı olması gerekir...Halkla ilişkiler görünümde daha basit kalmış gibi oluyor. (Uygulayıc1 8)

...Halkla ilişkiler tek paydaşa yönelik. Halk var. Mecralarla iletişim. Kurumsal iletişim bunun kapsamını değiştirdi. Gene belirli bir mecra kullanılıyor ama varyansları var. Kurumsal iletişimde yapılması gereken konu başlıkları çeşitlendi. Kurumsal iletişim geniş düşünülen bir iş. Eski zamanlarda ürün iletişimi yapılıyor ve bu halkla ilişkiler. (Uygulayıcı 7)

...Halkla ilişkilerin içi boşaltıldı. Bernays, halkla ilişkilerin propagandanın insanları rahatsız etmeyen biçimi olduğunu söylemiş. İnsanların zihninde olumsuz izlenim oluşturduğu için kurumsal iletişim daha uygun geliyor. Halkla ilişkiler deyince manipülasyon, spin geliyor. Bernays progagandayı keskin bulduğum için halkla ilişkilere çevirdim diyor...Kurumsal iletişim kulağa daha hoş bir kelime geliyor. İmajı onarmak çok zordur. Halkla ilişkiler deyince akla gelen kırmızı mini etek, file çorap. Oysa mesleğin cinsiyeti yok ki. Erkekler de çok başarılı. Halkla ilişkilerin yönetim fonksiyonu olduğu anlaşılmıyor. (Akademisyen 2)

\section{Halkla İlişkiler ve Kurumsal İletişim Nasıl Tanımlanıyor?}

Katılımcıların halkla ilişkiler ve kurumsal iletişim tanımlarına bakıldığında birbirine çok benzer tanımlar yapıldığı göze çarpmaktadır. Bu açıklamalar şu şekildedir:

...Kurumsal iletişim, bu işin kurumla ilgili olduğunu gösteriyor. Halkla ilişkilerdeki karşllıklı sempati yaratmak kurum tarafından, kurumun çıarına, daha pragmatik bir iletişim süreci. Halkla ilişkilerde karşılıklı çıkar, anlayış var. (Akademisyen 1)

...Kurumsal iletişim, bir kurumun bütünsel iletişim yaklaşımını stratejik bir plana dâhil eden ve bunu yayan bir yönetim dalı. Bütünsel ve stratejik. Halkla ilişkiler ise tanım olarak kamuoyuyla olan iletişimin yönetimi. (Uygulayıcı 2)

... İskandinav ülkelerindeki uygulamaları seviyorum. Halkla ilişkiler aracı bir merci gibi. Hedef kitlenin ne istediğini biliyor. Diyor ki kuruma da bu insanları mutlu etmek şunu şunu yapmalısın, kendini düzenlemelisin diyor. Halkla ilişkilerin misyonu bu olmalı. Arayıcı bir düzenleyici olmalı. (Akademisyen 2)

...Departman ismi kurumsal iletişim olunca biz her şeyin içinde içindeyiz. Medya ilişkilerini, kurum içi iletişim faaliyetlerini yönettik, yazılı çizili her şeyin içindeyiz, kurumsal, sosyal sorumluluğu yürütüyoruz. Halkla ilişkiler olunca bunların hiçbirini yapmıyorduk. Basın bülteni hazırlıyorduk, internet sayfasına girecek duyuruları yazıyorduk, yapıyorduk,. Yönetim faaliyetlerinin içinde biz yoktuk. Şimdi yönetimin içindeyiz. Biz yönlendiriyoruz. Eskiden bize verilen işi yapardık. Şimdi hayır bu böyle olmalı diyoruz. (Uygulayıcı 3)

Halkla ilişkilerde şirketin görüşlerini kamuya değil de kamunun görüşlerini şirkete yansitmalısın. (Akademisyen 3). 
...Halkla ilişkiler 3. parti işbirlikleri....Etkinliklerle ve medya ilişkileri. (Uygulayıcı 6)

...Kurumsal iletişim iş stratejilerini hayata geçirme ve iletişim stratejisini entegre biçimde yönetme biçimi. (Uygulayıc1 7)

...Kurumsal iletişim itibar yönetimi. İtibarı destekleyenler tüm paydaşlar. Halkla ilişkiler alanı içinde sadece basın var. (Uygulayıcı 8)

...Kurumsal iletişim. Daha açıklayıcı. Kurum var kurumsal iletişim iki kelime bir arada net. Halkla ilişkiler nedir? Sancılı anlaşılmadı gitti. Mesleki anlamda mesleğin saygınlığı anlaşılırlığı açısından uzun vadede çözecektir. (Uygulayıcı 1)

...Stratejik iletişim yönetimi. İletişimin de esas bir yönetim olduğunu göstermek. İş süreçlerini etkilediğini anlatmak. Yönetimde yer almak. (Uygulayıcı 2)

\section{Kurumsal İletişim ve Halkla İlişkilerde Başarı}

Katılımcılar genel olarak halkla ilişkilerin başarısı ile kurumsal iletişimin başarısını benzer sonuçlarla açıklamışlardır. Paydaşlarla iyi ilişkiler kurabilmek, kurum hakkında olumlu algılar yaratmak ve tutarlı bir iletişimle uyumlu mesajlar vermek özellikle üzerinde durulan konular olmuştur. Katılımcıların görüşlerinden bazıları şu şekildedir:

...Hangi isimle anılırsa anılsın, başarı için benzer sonuçlar elde ediliyor (Uygulayıcı 4)

...Amaçlara ve hedeflere ulaşabiliyorsanız ve bunu ölçümleyebiliyorsanız...Kriz dönemlerinde paydaşların desteğini alabiliyorsanız başarılısınız. (Akademisyen 1).

...Bilinirlik, hedef kitlenin sempati duyması, olumlu marka imajı, basın yansımaları. Marka sadakati. Kendinden bahsettiyorsa kurumsal iletişim başarılı. Hem kurumsal anlamda hem de sosyal medya kanallarının bütününde güzel bir görsellik tutarlı bir görünüm başarıdır. (Uygulayıc1 1)

...Tek bir alanda değil, şirketin tüm faaliyetlerinde yapılan çalışmaların kamuoyuna yansıtılması. Tüm çarkların doğru dönmesi gerekiyor. Operasyonel süreçten müşteri temas noktasına, insan kaynakları iletişimine kadar. Şirketin tüm çarklarının hep beraber hareket ederek dönüp bir mesajla dışarı çıkabilmesi. (Uygulayıcı 2)

...Her ikisi içinde etik uygulamalar, dürüstlük. Kurum içinde insanları mutlu etmek, dışarı da başarıyı getiriyor. İçini mutlu edersen dişarı da oluyor. (Akademisyen 2)

...Halkla ilişkilerde başarı sosyal sorumluluk projesi ve ödül...Kurumsal iletişimde başarıdan bahsedeceksek soyut bir kavram. Raporlar ve iş yaptığımızın raporları ve ölçüm araçlarını kullanma. (Uygulayıc1 5)

...Değerlendirme yaptığınız konuyu başarıya bağlamakta zorlanıyorsunuz. Kurumsal iletişimde başarı ölçümlemenin başarı kriterine bağlı. (Uygulayıcı 7)

...Kurumsal iletişimde başarı tüm departmanların birbirlerini anlaması ve ortak akla sahip olması. Ortak mesaj ve kamuların iyi idare edilmesi. (Akademisyen 5) 
...Kurumsal iletişimde her bir paydaşın kuruma ilişkin algısının nasıl evrildiği-izlenim. (Akademisyen 6)

...Halkla ilişkilerde başarı, kurum içi stratejilerle uyumlu halkla ilişkiler yönetimi. Kurumsal iletişimde başarı bir itibar yönetimi, vizyon yönetimi, dışarıya en iyi şekilde yansıtmak. (Uygulayıc16)

...Halkla ilişkilerde başarı doğru ve iyi bir iletişim kanalı yaratmak...sürdürülebilir ve tutarlı bir ilişki yaratmak. (Uygulayıcı 8 )

...Eğer gerçekten halkla ilişkiler yapılıyorsa, halkın da kurumun nezdinde temsil edilebildiği, halkın onayının aldığı yerde başarı olur... Gerçek temsille birlikte ortak karar verebilme, alınan kararlardan karşılıklı memnuniyet, gerçek bir kazan kazan ilişkisi olursa, hatta halkın kazanabildiği bir ilişki söz konusu olabilirse. (Akademisyen 1).

Akademisyenlerden biri ise halkla ilişkilerin başarısı ile kurumsal iletişimin başarısını çok net şekilde şu sözlerle ayırmıştır:

...Kurumsal iletişimin başarısı, kurumun iletişiminin başarısı demek. Halkla ilişkilerin başarısı, paydaşların/kamuların görüşlerini kuruma aktarabilmek, onlarla anlaşmak, onların ihtiyaçlarını ve gereksinimlerini karşılamak...Halkla ilişkilerciler duyarlılığa sahip olmalı. Kamuların görüşleri masaya taşınmalı. Diyalog, uzlaşma kültürü çok önemli. Bu becerileri elde etmeli. İlişki yönetimi becerisi olacak. Kahveye gidip köylülerle konuşacak. Halkla ilişkiler kamuya gider. Kurumsal iletişim kuruma çağırır herhalde. (Gülüyor). (Akademisyen 3)

\section{Başarıyı Etkileyen Faktörler}

Katılımcılar halkla ilişkiler ve kurumsal iletişimin başarısını etkileyen faktörler içinde yönetimin bakışı, farklı disiplinlerde bilgiye sahip olmak, temel iletişim becerilerine sahip olmak, iyi bir kadronun olması ve bütçe gibi gerekliliklerden söz etmiştir. Bazı katılımcıların görüşleri şöyledir:

.... İçeriden yönetimin bakış açısı. Bir holdingse şahıs şirketiyse de vizyonu, bakış açısı önemli, işin profesyonelliğine saygı duyup, uzmanlara bırakması çok önemli. Birim yönetisinin vizyonu çok önemli. Bütçe. Ajans seçimi, yaratıcı veya organizyon ajans seçimi. Bilgi beceri. (Uygulayıc1 1).

...Tolerans, ne olursa olsun etik uygulamalar, bedel ne olursa olsun ödemek, dürüstçe yönetmek, psikoloji, sosyoloji, antropoloji, pazarlama bilmek, genel kültür, her türü insanla iletişim kurma becerisi geliştirmek, egolarını bir kenara bırakabilmek, sistematize bir çalışma ortaya çıkarmak. (Akademisyen 2).

...Ne zaman, neyi, ne şekilde konuşacağız. Kurumsal işlerin yavaşlamasını sağlayan etki kadro ve bütçelerden kadronun kısıtlı olması. (Uygulayıcı 5)

...Doğru insanla çalışmak, ayrı profesyonellik. (Uygulayıcı 6) 


\section{Uygulayıcıların Nitelikleri}

Katılımcılar halkla ilişkiler ve kurumsal iletişim uygulayıcılarının benzer niteliklere sahip olması gerektiğinden söz etmişlerdir. Bunun yanında bazı katılımcılar kurumsal iletişim uygulayıcılarının işletme fonksiyonlarına daha fazla hâkim olması beklentisinin altını çizerken; halkla ilişkiler uygulayıcılarının sosyal bir hassasiyete sahip olması gerektiğine vurgu yapmıştır:

...Kurumda yapmak istediklerini anlatabilme yeteneği olmalı, sayılar verebilme, ölçümler verebilme. Kurumsal iletişim elemanı daha işletmeye yakın, işletme fonksiyonlarına hâkim, planlayabilir, örgütleyebilir, biraz muhasebeden bile anlaması gerekebilir, yatırımın geri dönüşümü hesaplayabilmeeli, daha kar amaçlı. Yatırım maliyetini ve kazandırdığını söyleyebilir biri olmalı. (Akademisyen 1)

...Bütün iş süreçlerine hakim olmalı. İşin teknik boyutunu bilmeli. İnsan kaynaklarını bilmeli. Özgüvenli, istikrarlı, akılcıl, rakamsal ve duygusal değerlere hâkim...Daha kamuoyuna dönük işler yapması, daha kendini ifade etmesi, fiziksel olarak bir yerde bulunması, kampanya sürecini yürütmekte birebir ilişkileri yönetmesi gerekmekte. Daha fazla kişisel ilişki yönetimi. Halkla ilişkilerci daha duygusal değerlere sahip. (Uygulayıcı 2)

...Kurumsal iletişim ve halkla ilişkiler aynı. Entellektüel zeka seviyesi yüksek olmalı. Kesinlikle aykırı ve yaratıcı olmalı. Kendi diline çok hâkim olmalı. Çok okuyup çok araştırmalı, sekiz gözü olmalı. Herşeye meraklı, herşeyden az biraz anlamalı. Çok sosyal, kesinlikle iletişim fakültesi mezunu olmalı. Dış görünüşten çok beyninin içine bakarım. Genel iletişim, pazarlama, organizasyon yönetim. Dil bilgisi, yazarlık, yaratıcı yazarlık. Detaycllık ve kontrol. Psikoloji, sosyoloji, sosyal psikoloji... Her bir alanda eğitim sosyal psikoloiji, pazarlama, reklam, biraz grafik renk matbaa bilgisi. Reklam, uygulama ağırlıklı olmalı. Yerinde uygulama gibi dersler. Okulda atölye gibi etkinlikler. Okuldan kitapların arasından çıktığında biliyor olmalısın. (Uygulayıcı 1)

...İlla iletişim fakültesinden çıkması gerekmiyor. Yazı bir anda olmuyor. Zaten yatkın olursun. Yazmak da yazarlık da gelişir. (Uygulayıcı 8)

...İşi iletişimciler yürütmeli. Ekonomi mezunu olsun kurumsal duruşu olsun bana yeter diyor. Bence böyle değil. (Uygulayıcı 3)

...Kurumsal iletişimci kurum için çalıştığının bilincinde olmalı, dışarıdan içeriye çok veri alabilmeli. İnsanları nasıl yönlendireceğini bilmen gerekiyor, psikoloji, sosyoloji konularında ehil, meraklı. Düzenli sistematik çalışabilen. Kalemin iyi olmalı. (Akademisyen 1)

...Kurumsal iletişimci için...Iyi organize etme becerisi, yeteneği, planlı programlı disiplinli, detayc1, kontrolcü, iyi iletişim bilgisi, güçlü iletişimi olan, kendini iyi ifade edebilen, sözlü ve yazılı şekilde. İyi yazma yeteneği önemli. (Uygulayıcı 1)

...Halkla ilişkiler uygulayıcısı...Daha halkın içinde, halkın sosyal yapısını daha iyi bilen, farklı gruplarla konuşabileni çok corporate havası olması gerekmiyor, tamamen şirketin çıkarına değil, kurumu dışarıda savunabilen, dışarıyı kurumda savunabilen. (Akademisyen 1)

...Yazı. Eskiden halkla ilişkilerde usta çıraklık ilişkisi vardı. (Uygulayıcı 7) 
...Halkla ilişkilercilerin sosyal hassasiyeti olmalı. (Akademisyen 4)

\section{Tartışma ve Sonuç}

Bu çalışmada özellikle son yıllarda gerek akademinin gerekse uygulamanın tartışma konularından biri olan halkla ilişkiler ve kurumsal iletişim arasındaki kavram kargaşasını akademisyen ve uygulayıcı gözüyle ortaya koymak amacıyla hareket edilmiştir. Böylece ülkemizdeki duruma ilişkin bir durum tespiti yapılmaya çalışılmıştır. Yüzyüze görüşmelerin yapıldığı araştırmada, konuya ilişkin derinlemesine veriler elde edilmiştir. Öncelikle kurumsal iletişim kavramı araştırmaya katılan sektörde çalışan uygulayıcıların tamamı tarafından halkla ilişkiler yerine tercih edilmektedir. Son zamanlarda kurumların departman isimlerini kurumsal iletişim olarak değiştirdiklerine sıklıkla tanık oluyoruz. İletişimcilerin de çalıştıkları departmanın isminin kurumsal iletişim olmasından dolayı memnun olduklarını araştırma verilere dayanarak söylemek olasıdır. Uygulayıcıların görüşlerine göre, kurumsal iletişim daha kapsayıcıdır, işletme fonksiyonlarına daha yakındır, daha fazla görevi içermektedir ve dolayısıyla üst yönetimden daha fazla destek görmektedir. Örneğin, katılımcılardan biri çalıştı̆̆ departman isminin halkla ilişkilerden kurumsal iletişime çevrildiğinde, yönetimin bakış açısının değiştiğini ve başka departmanlarda çalışan kişilerin kendisine farklı davranmaya başladığını vurgulamıştır. Bunun gibi faktörler nedeniyle kurumsal iletişimin gün geçtikçe daha fazla departman tarafından tercih edilen bir isim olacağını öngörmek mümkündür.

Katılımcılara kurumsal iletişim ile halkla ilişkilerin aynı olup olmadığı sorulduğunda bazıları aynı, bazıları ise aynı olmadığını cevabını vermektedir. Bazı katılımcılar paydaş, sürdürebilirlik gibi temel kavramlar üzerinden kurumsal iletişimi farklılaştırarak daha uygun bir isim olarak değerlendirse de; çoğu katılımcı uygulamalardan söz ederken kurumsal iletişim ve halkla ilişkiler arasındaki bir farktan söz etmemiştir. Bazı katılımcılar kurumsal iletişim ismi kullanıldığında departmanın işletme fonksiyonlarına daha yakın görüldügünü vurgulasa da, uygulamaya döküldügünde hangi uygulamalar nedeniyle farklılaştığı sorusunun cevabını vermek çok güçtür. Dolayısıyla şu uygulamalar halkla ilişkilerin, şu uygulamalar kurumsal iletişimin demek mümkün olmadığı gibi; aralarındaki (varsa) çizgiyi netleştirmek de oldukça zordur. Şöyle ki katılımcılar tarafından sözü edilen itibar, imaj, sosyal sorumluluk, kriz, sorun yönetimi, sürdürülebilirlik gibi kavramların hiçbiri ne yalnızca halkla ilişkilerin ne de yalnızca kurumsal iletişimdir. Bu durumda halkla ilişkilerle kurumsal iletişim arasındaki farkın (eğer varsa) ne olduğunu ortaya koymak oldukça zor olacaktır.

Katılımcılar kurumsal iletişimin tercih edilme nedenleri arasında daha kapsayıcı olması, daha stratejik olması, kurumda daha üst bir konumda yer alabilmesi gibi faktörleri saymaktadır. Bunların yanı sıra halkla ilişkilerin geçmişinden gelen olumsuzluklar ve günümüzdeki etkileri belki de kurumsal iletişim kavramının popüleritesini arttıran en önemli husus olmaktadır. Şöyle ki katılımcılardan birinin de vurguladığı gibi Edward Bernays'in "Propaganda çok savaşı anımsatıyordu, bu yüzden halkla ilişkileri tercih ettim” demesi de mesleğin babalarından biri olarak sayılan kişinin ağzından halkla ilişkilerin nasıl görüldüğüne ilişkin önemli bir mesajdır. Bu durumda kurumsal iletişim tercihi, kurumsal iletişimin sahip olduklarından değil de halkla ilişkilerin sahip olduğu olumsuzluklardan mı kaynaklanıyor sorusunu ortaya çıkarmaktadır. Dolayısıyla halkla ilişkilerin 
geçmişinden kurtulmak için kurumların iletişimini yürüten departmana farklı bir isim verilmesi bir çıkış noktası olarak görülebilmektedir. İleride kurumsal iletişim ismi de olumsuz algılanırsa, iletişimciler yeni bir kavram arayışına mı girecektir sorusunun üzerinde önemle durulmalıdır.

Teorik kökenlerine bakıldığında kurumsal iletişim, daha çok işletme-yönetim akademisyenleri tarafından kullanılan bir kavram olarak karşımıza çıkmaktadır. Halkla ilişkiler yerine kurumsal iletişimi tercih etmek, kamuların yeteri kadar temsil edilememesi anlamına mı gelecektir sorusu iletişim uygulayacılarının cevaplaması gereken hususlardan biridir. Şöyle ki ülkemizde eğitim veren üniversitelerde oldukça yüksek sayıda halkla ilişkiler bölümü bulunmaktadır. Halkla ilişkilerin meslekleşmesi açısından bu bölümlerden mezun kişilerin istihdam edilmesini talep ederken; kurumsal iletişim ismini kullanmak alanı başka bölümlerden mezun kişilere bırakmak anlamına da gelebilir. Halihazırda halkla ilişkilerde başka bölümlerden mezun kişiler de çokça istihdam edilirken; kurumsal iletişim denildiğinde işletme fonskiyonlarına ilişkin daha fazla eğitim almış kişilerin istihdamı da kaçınılmaz olacaktır. Oysa ki halkla ilişkiler yalnızca kurumların temsili değildir. Katılımcılardan birinin de ifade ettiği gibi halkla ilişkilerin başarısı, yalnızca kurumların başarısı olamaz. Halkla ilişkilerin başarısı, kamuların ne kadar temsil edildiğine de bağlıdır. Bu noktada halkla ilişkiler uygulayıcılarının yalnızca işletme perspektifinden değil, kamuların gözünden de konuları değerlendirmesi gereklidir.

Çalışma kapsamında elde edilen verilere dayalı olarak kurumsal iletişimin uygulama dünyasında tercih edilirliğinin hızla artacağı öngörülüyor olsa da, iki uygulama alanı arasındaki farkın net olarak ortaya konulması en azından şimdilik mümkün görünmemektedir. Benzer eğitimleri almış ve benzer niteliklere sahip olması beklenen kişilerce yerine getirilen, aynı uygulamalara sahip iki alanı birbirinden ayırmak üzerinde çokça düşünülmesi gereken bir husustur.

Bu çalışma kapsamında nitel bir yöntem kullanıldığından, nicel yöntemlere kıyasla daha küçük bir gruba ulaşılmış, ancak derinlemesine veriler elde edilmiştir. Gelecek çalışmalarda daha büyük katılımcı sayılarına ulaşıldığında, daha genellenebilir veriler elde etmek mümkün olabilecektir.

\section{Kaynakça}

Canöz, K. (2008). Kamuda halkla ilişkierin yeni yüzü: Bilgi edinme yasası. Selçuk Iletişim Dergisi, 5(3), 141-152.

Christensen, L. T. ve Cornelissen, J. (2011). Bridging corporate and organizational communication: Review, development and a look to the future. Management Communication Quarterly, 25(3) 383-414.

Coombs, T. W. ve Holladay, S. J. (2007). It's not just PR: Public relations in society. MA: Blackwell Publishing.

Cornelissen, J. P. (2008) Corporate communication: A guide to theory and practice. London: Sage.

Temel Eğinli, A. (2014). Halkla ilişkiler sadece iyi kişilerarası ilişkiler kurmak değildir?. A. Temel Eğinli (Haz.), Halkla ilişkiler ne değildir? içinde (s. 67-94). Istanbul: Say Yayınları.

Ertürk, K. Ö. (2016). Dönüşen iletişim paradigmasının halkla ilişkilerdeki iletişim politikasına etkileri (Tarihsel bir analiz). Journal of World of Turks, 8(1), 205-220.

Grunig, J. E. (2009). Paradigms of global public relations in an age of digitalisation. PRism, 6(2), 1-19.

Hutton, J. G. (1999). The definition, dimensions, and domain of public relations. Public Relations Review, 25(2), 199-214. 
Illia, L. ve Balmer, J. M. T. (2012). Corporate communication and corporate marketing: Their nature, histories, differences and similarities. Corporate Communications: An International Journal, 17(4), 415-433.

Jain, R. ve Bain, M. (2017). Delivering higher value through higher performance: Insights on performance evaluation and talent management in corporate communication. Public Relations Journal, 11(1), 1-18.

Kalender, A. (2013). Kavram olarak halkla ilişkiler, Dünyada ve Türkiye’de halkla ilişkilerin tarihsel gelişimi. A. Z. Özgür (Haz.), Halkla İlişkiler içinde (s. 2-29). Eskişehir: Anadolu Üniversitesi Açıköğretim Fakültesi Yayını No: 1676.

Köseoğlu, Ö. (2014). Halkla ilişkiler: Duyurumdan yansitıcı role. A. Temel Eğinli (Haz.), Halkla ilişkiler ne değildir? içinde (s. 9-66). Istanbul: Say Yayınları.

Mazzei, A. (2014). A multidisciplinary approach for a new understanding of corporate communication. Corporate Communications: An International Journal, 19(2), 216-230.

Mihai, R. (2017). Corporate communication management: A management approach. Valahian Journal of Economic Studies, 8(2), 103-110.

Mohamad, B. ve Bakar, H. A. (2018). Corporate communication and strategic management: history, operational concept and integration. Proceedings of the Advances in Social Science, Education and Humanities Research (ASSEHR), 186, 15th International Symposium on Management (INSYMA 2018), 240.244.

Podnar, K. (2015). Corporate communication: A marketing viewpoint. New York: Routledge.

Steyn, P. ve Puth, G. (2010). Corporate communication strategy. Cape Town: Heinemann.

Smith, R. D. (2009). Strategic planning for public relations. New York: Routledge.

Tekvar, S. O. (2017). Habermas ve Bourdieu’nün temel kavramları üzerinden halkla ilişkileri yeniden düşünmek. Erciyes Iletişim Dergisi “Akademia”, 5(1), 82-94.

Tosun, N. Babür (2003). Kurumsal iletişim sürecinde reklamin ve imaj yönetiminin bütünleşik konumu. Marmara Üniversitesi İ.İ.B.F. Dergisi, 18(1), 173-191.

Tuncel, H. (2009). Halkla ilişkilerin adlandırma sorunsalı üzerine bir değerlendirme. Marmara İletişim Dergisi, (14), 109-123.

van Riel, C. B. M. (1995). Principles of corporate communication. Essex: Pearson.

van Riel, C. B. M. ve Fombrun, C. J. (2007). Essentials of corporate communication. New York: Routledge.

van Ruler, B. ve Vercic, D. (2002). The bled manifesto on public relations. 12.03.2018 tarihinde www.bledcom. com adresinden edinilmiştir.

Wilcox, D. ve Cameron, G. (2012). Public relations strategies and tactics. Boston, MA: Allyn and Bacon.

Woo, C. W., Gorpe, S. ve Kalupa, F. (2013). Professional perspectives: An international study of professionalism, ethics and social value of public relations. Proceedings of $11^{\text {th }}$ International Communication in the Millennium Symposium, Minnesota, USA. 20 - 24 Mays 2013.

Yıldız, N. (2010). Halkla ilişkilerde kavramlar, sınırlar, sorunlar. Selçuk İletişim Dergisi, 6(2), 24-32.

Zerfass, A. (2008). Corporate Communication revisited: Integrating business strategy and strategic communication. A. Zerfass, B. van Ruler ve K. Sriramesh (Haz.), Public Relations Research içinde (s. 6596). VS Verlag für Sozialwissenschaften.

Zerfass, A. ve Viertmann, C. (2017). Creating business value through corporate communication: A theorybased framework and its practical application. Journal of Communication Management, 21(1), 68-81. 


\title{
Public Relations or Corporate Communication? Concept Discussions of Academics and Professionals
}

\author{
Burcu ÖKSÜZ** \\ Serra GÖRPE***
}

Public relations is usually misunderstood, and the nature of what it is that public relations professionals do is not quite known. Beyond only being a societal perception, it is possible to state that this is a situation which public relations professionals find themselves facing quite frequently. When compared with other more-established professional fields; we see public relations trying to prove its worth to its target groups, customers and to society as a whole. Since every country's level of development is different from one another; there tends to be variations and contrasts in its practice. Coombs and Holladay (2007) have summarized the criticisms brought against public relations in six key points. These points are: public relations does not represent the truth and tends to twist it, albeit while not blatantly lying. The origins of public relations lean upon manipulation and persuasion, and that the initiatory practices in its field were inclined toward unethical persuasion and propaganda. Public relations empowers already powerful corporations and other institutions. It serves only the interests of powerful corporations, thus weakening the democratic process. The thought that the only way society can escape the influence of public relations is by understanding it in its fullest sense. And lastly; the practice of public relations is limited to publicity and visibility in the media (pp. 14-16).

Corporate communication is becoming more widespread with each passing day, and according to some, it implies a management function called public relations. Steyn and Puth (2010) specify that the term "corporate communication" implies a more "accurate and valid" description that modern organizations need, and that since earlier years such as 1992, the usage of the term "corporate communication" has been preferred to "public relations" (pp. 2-3). Justifying the rendering of the name of public relations void by synonymizing public relations with corporate communication would not be accurate. Currently, there are both graduate and postgraduate courses being offered at universities; academic research being conducted, and refereed scientific journals and books being

\footnotetext{
** Assoc. Prof. Dr., İzmir Kâtip Çelebi Üniversitesi, Medya ve İletişim Bölümü, İzmir, Türkiye, burcu.oksuz@ikc.edu.tr. Orcid ID: 0000-0003-4195-9261.

*** Prof. Dr., University of Sharjah, College of Communication, Sharjah, Birleşik Arap Emirlikleri, tgorpe@sharjah.ac.ae. Orcid ID: 0000-0002-9634-2827.
} 
published in the name of public relations. In other terms, public relations has established its place in academic literature (Tuncel, 2009, pp. 121-122).

The result of public relations being used erroneously by the media is a collective misconception of it by society. Manipulation, propaganda, prevaricating and image - making in the service of corporate interest are all descriptions used to describe public relations. The studies conducted by pertinent academics from different countries about the representation of public relations in the media portrays this perception (Woo et al., 2013). When we look at the development of public relations departments in the corporate world of The United States, we see that the initial functions were promotion and advertising (Wilcox, 2012). Later these functions evolved being expressed through terms such as: integrated marketing communications, integrated communications or holistic communications; a holistic approach has become a prominent constituent of public relations' business objectives.

Tosun (2003) emphasizes that dubbing public relations as synonymous with corporate communication would be inaccurate; as 'management communication', 'organizational communication' and 'integrated marketing communications' which are shown as components of corporate communications, may not always operate within public relations (p. 176). It is emphasized that the roots marketing public relations, which contribute to marketing communications is in the history of public relations. For example, Edward Bernays' 1929 campaign - which encouraged women to smoke cigarettes - is an example of a marketing public relations campaign. Marketing public relations advocate Thomas Harris states that public relations understands very well the target consumer group, and that based on successful applications implemented in our modern day, public relations' reputational contributions can be seen in marketing as well (Smith, 2009, pp. 5-8).

\section{Public Relations}

In Turkey, public relations practices in the modern sense first started during the 1960s in the state (governmental) sector. In order to explain the relation between the state (government) and its citizens, the English term "public relations" was first translated into Turkish as "amme münasebetleri", then "halkla münasebetleri," then finally as "halkla ilişkiler" (Tuncel, 2009, p. 110). The translation of "public relations" into Turkish as "halkla ilişkiler" commenced an interpretation quandary since the word "halk" is generally perceived to mean "public/society"; it, for a long time, was described as relations with the public/society. Both the word "relations" and the public relations profession are perceived as forming connections with others, thus restricting the notion of public relations and causing it to be perceived as narrow-scoped (Temel Eğinli, 2014, p. 67).

Public relations has been characterized not by what it is, but by what it does. When asking a professional to define what public relations is, receiving a list comprised of to publicize, press agentry, (corporate) advertising, issue management and media relations, is most probable (Köseoğlu, 2014, p. 11). The primary criticism brought against the public relations definitions is that they focus on the effects of public relations and specific tasks of professionals instead of its fundamental purpose. Another widespread criticism is that the academic definitions are normative and peremptory as opposed to the more authentic description brought forth by commercial and political definitions 
(Hutton, 1999, p. 201). Tekvar (2017) points out that until recently public relations was interpreted as "planned-out communication operations (practices) carried out so that the organization can reach its goal," and that both public relations and communications operations are unilateral, single-sided, positivist, automated, and lean upon monologues (p. 83).

Kalender (2013, p. 4) emphasizes that public relations can be defined as a management function, or communication management, but in recent times there have been definitions defining it as relationship management. Similarly, Yıldız (2010) states "instead of looking with a trite generalization of the definition such as 'building bridges between organizations and the pertaining public', we should come to see it as the unignorable field which yields the capacity to change the world and society through the pertaining public" (p. 25). The fundamental principle of public relations is providing the public with accurate information, to strive to create a positive image about an institution or person, and to create reciprocal understanding all within the realm of legitimacy (Canöz, 2008, p 141). The objective of public relations is carried out not through the embracement of its works by target groups, but by the affirmance (embracement) of these functions in reciprocal understanding, auspicious intentions and tolerance. The fulfillment of this objective is linked to both being aware of the public's wishes, expectations and needs; and to informing the target audience of its objectives and ambitions (Ertürk, 2016, p. 211).

van Ruler and Vercic (2002) describe the four characteristics of public relations in Europe as so:

Reflective: This role is related to organizational standards, values, views, and strives for the development of organizational missions and strategies.

Managemental: This role pertains to commercial and other (internal and external) stakeholder groups; the public opinion, and the execution of organizational missions and strategies.

Operational: This role pertains to the execution of communication plans.

Educational: This role pertains to the organization members' minds and actions and targets the internal stakeholder groups. (p. 14)

Grunig (2009) summarizes the essential principles of public relations as the following:

- $\quad$ Strengthening public relations

- Integrated communication function

- Separate management function

- Management carried out by strategic managers as opposed to communication technicians or administrative directors

- $\quad$ Partaking in strategic management

- Two-way and symmetrical communications

- $\quad$ Diversity

- $\quad$ Ethical (p. 2) 


\section{Corporate Communication}

Although literature of corporate communication goes as far back as the 1970s; during this time, corporate communication was known as public relations and was under the jurisdiction of the public relations department (Mohamad ve Bakar, 2018, p. 240). Podnar (2015) defines corporate communication as the synchronization of one institution's different communicative aspects and the integration of the messages which they dispatch. Van Riel (1995) on the other hand states that corporate communication is a supervisory instrument which harmonizes all forms of inner and outer communications intended for the stakeholders. Another definition states: "The integration of all predisposed communications operations being carried out so that the organization may reach and execute its goals" (Tosun, 2003, p. 175). Mihai (2017, p. 104) emphasizes that corporate communication management also incorporates public relations, internal communication, investor relations and corporate advertising. van Riel and Fombrun (2007) state that corporate communication can be separated into these three dimensions: management communication, organizational communication, and marketing communications.

The role of the corporate communicator in the daily functions of the organizations and its valueadded contribution is becoming more and more vital. (Jain ve Bain, 2017, p. 4). According to Zerfass (2008) corporate communication primarily aims to inform and create meaning, and as a result of this, influence stakeholders. Because of this, corporate communication serves to provide both services and products (success), and also to create abstract values (potential success in future) in the organizations (2008). Corporate communication is a valuable resource for both listening to, and learning from the environment. At the same time, it is a key factor for creating a wide frame of support for corporate activities, repositioning the company, and supporting concordant strategies (Zerfass and Viertmann, 2017, p. 72).

Although Cornelissen (2008) points out that corporate communication, in broad terms, conveys the meaning of message (intelligence) flow especially from big corporations, in our modern day corporate communication underlines the fact that it is possible to apply this meaning to many different organizations. There is a difference between corporate and other types of organizational communication. For example, there are clear-cut target audiences for organizational communication functions such as advertising and employee relations, but that is not the case for corporate communication. Corporate communication exist to create and conserve amiable corporate reputation amongst stakeholders (2008). There is a collective mindset within the wide scope of corporate communication: 'approaching organizational communication with integrity and collectivity'. When looking at its roots in Latin; the word "corpus" means a merging of a collective entity into one body, which metaphorically invokes unity and collectivity (Christensen and Cornelissen, 2011, p. 387).

Corporate communications is a managemental function with three fundamental aims brought forth by various researchers and academics. One of them is the company establishing auspicious relations with affiliated (dependent) groups. Another being: evaluating social inclinations and by means of offering corporate policies, helping the company to renew itself and proactively keep up with changes in society. Another function is supporting marketing campaigns by keeping all communication under one strategy (Illia and Balmer, 2012, p. 418). 


\section{Research}

The purpose of the paper is to look at the territories, the nature, and the differences and similarities between public relations and corporate communication. The paper analyzes these territories through literature review in terms of their definitions and scope. In addition to the theoretical point of view, the paper also aims to investigate the current understanding of these terms by conducting semi-structured interviews with Turkish academics and professionals in the cities of Istanbul and Izmir. Public relations is a usually misunderstood concept basically for two main reasons: one is related with the negative portrayal of public relations in the media, and the other one is that it stills suffers from its roots which were initially related to persuasion and propaganda. When it comes to corporate communication, we can say that different disciplines have produced different conceptualizations of corporate communication. At one point, discussing terminologies of public relations and corporate communication can be interpreted as an unnecessary attempt, but definitions/concepts should be studied, discussed, agreed upon and developed as well. Otherwise, individual interpretations of public relations and corporate communication limit or prevent the objective understanding of the theoretical and practical framework. The goal of this study is to explore the conceptualization of public relations and corporate communication ideas by academics and professionals, and to contribute to the academic literature and its practice. In this respect, a qualitative study has been conducted. Semi-structured, face-to-face interviews took place in Istanbul and Izmir with practitioners as well as academics at the rank of associate professor or professor. A total of 14 people were interviewed. The practitioners represented different sectors such as health, energy, automotive, food, education, public and white goods sectors, and all were in high rank corporate communications posts. When compared to the quantitative method, although a small group was reached, interviews that lasted 30 to 90 minutes each generated more in-depth data about the issues addressed. Data on how the concepts of public relations and corporate communication are understood and defined, how success is defined, and which factors affect success were gathered. The interviews took place between $28 \mathrm{March}$ and 14 April 2018. Our findings reveal that all practitioners prefer corporate communication over public relations. They view corporate communication as more comprehensive, closer to the business function, and as having more support from top management. The negative past of public relations is stated as another reason. Academics seemed to favor public relations over corporate communication. Academics who preferred the former explained that public relations includes the public, and it does not see its stakeholders as an economic unit only. Most interviewees did not emphasize a prominent difference between corporate communication and public relations. In general, the success factors involved in corporate communication and public relations were reported as being similar. It was mentioned that practitioners have similar qualifications, but some participants stress that corporate communication practitioners need to be knowledgeable about business practices. The factors affecting the success of both public relations and corporate communication functions are mentioned as follows: management's approach (support), knowledge of different disciplines, possession of basic communication skills, and a good working team and budget. The study leaves us with further questions to elaborate upon and deliberate: as stated, the preference for corporate communication over public relations can be attributed to some 
extent to the negative connotations of public relations, but what will happen if one day corporate communication also carries negative perceptions? Will other alternative names be generated? Moreover, choosing corporate communication over public relations can endanger the representation of the people in society. We also discuss the implications of our findings in terms of education and professionalism in the field of public relations.basic communication skills, and a good working team and budget. The study leaves us with further questions to elaborate upon and deliberate: as stated, the preference for corporate communication over public relations can be attributed to some extent to the negative connotations of public relations, but what will happen if one day corporate communication also carries negative perceptions? Will other alternative names be generated? Moreover, choosing corporate communication over public relations can endanger the representation of the people in society. We also discuss the implications of our findings in terms of education and professionalism in the field of public relations. 